\title{
Smart Energy Monitors Technology for Energy Conservation at Ashongman in Accra
}

\author{
Anthony Bawa, Lewis Maxwell Selby \\ Department of Computer Science, Catholic Institute of Business and Technology (CIBT), Accra, Ghana \\ Email: bawaanthony@gmail.com
}

How to cite this paper: Bawa, A. and Selby, L.M. (2018) Smart Energy Monitors Technology for Energy Conservation at Ashongman in Accra. Open Journal of Energy Efficiency, 7, 129-141.

https://doi.org/10.4236/ojee.2018.74009

Received: September 30, 2018

Accepted: December 11, 2018

Published: December 14, 2018

Copyright ( $) 2018$ by authors and Scientific Research Publishing Inc. This work is licensed under the Creative Commons Attribution International License (CC BY 4.0).

http://creativecommons.org/licenses/by/4.0/

(c) (i) Open Access

\begin{abstract}
This study investigates the use of Smart Energy Monitors (SEMs) technology which has been introduced to help electricity consumers conserve energy and to ensure energy efficiency among residents in Ashongman, a suburb of Accra. Ghana as a developing country has gone through an energy crisis recently. There has been a shortfall of electricity generation capacity where demand has exceeded supply, which resulted in load shedding management. This study seeks to find out the energy conservation habits among Ghanaian residents at Ashongman and also to investigate the use of SEMs for energy conservation. The findings of the study showed $16 \%$ of respondents were aware of the benefits of SEMs in electricity conservation whilst $84 \%$ did not know. $72.7 \%$ of the respondents who were aware of SMEs have used it whilst $27.3 \%$ of respondents who aware of SEMs have not used it for energy conservation purposes. The findings also further indicated the challenges respondents face in conserving energy in their homes and the measures that need to be put in place to ensure energy efficiency. On the basis of the findings, it is recommended for the Energy Commission and Electricity Company of Ghana that, there should be effective policy to educate consumers on adapting SEMs technology for energy conservation.
\end{abstract}

\section{Keywords}

Energy Conservation, Smart Energy Monitors, Electricity

\section{Introduction}

Energy plays a key role in achieving the desired economic growth of a country. The entire fabric of developmental goals is webbed around a successful energy strategy. Energy is vital for the creation of wealth and improvement of social welfare; this means that adequate and reliable supply of energy is required to 
ensure sustainable development. However, the use of primary energy, most of the time results in waste; they are harnessed from limited resources which are considered environmentally unsustainable. The increasing rate of environmental problems related to energy use has led to a growing interest in issues of sustainable development thereby leading to a challenge of decoupling of economic growth and energy use. According to Chakarvarti (2011) [1] the prudent use of energy to ensure energy which is conserved can be grouped into two (2) concepts namely; energy efficiency and energy management. There is a need for energy conservation all over the world because of the increasing cost of electricity and also getting emission down to acceptable levels. Dai, Wu et al. (2009) [2] explain that a properly constructed system must be adopted by governments and regulators of energy to regulate and address energy conservation. The electricity, gas and oil market for some time now have provided significant benefits to industry and for local consumption. "Electricity is having a difficult time-or, rather, making it has never been tricky. Oil and gas are rapidly running out, coal is dirty, wind power and solar panels still aren't completely competitive, nuclear worries people" [3]. The idea of energy conservation is not new and thus the need for electricity consumers to cut down the expenditure on energy in order to reduce cost of consumption in their daily activities.

Ghana as a lower-middle income country has had its energy challenges in recent times from 2013 to 2015 . The country has gone through a load schedule management locally known as "dumsor" in a native language. Ghana's total electricity generation capacity as at 2014, stood at 2831 Megawatts, which consist of $64.7 \%$ hydro, $34.75 \%$ thermal and $0.05 \%$ solar power [4]. According to GRIDCO, Ghana's peak energy demand ranged between 1980 - $2300 \mathrm{MW}$, the total load from the transmission grid was 2061 MW in 2014, which is $6 \%$ more than in 2013 [5]. It is expected that Ghana needs about 5\% - 7\% additional generation capacity for it to attain the full middle-income status with energy sufficiency. The need for energy conservation among Ghanaians, particularly in the wake of the worsening energy crisis cannot be over emphasized. The Energy Commission (EC) is the mandated body to ensure energy efficiency in the country and as well educate electricity consumers on energy conservation and the use of sustainable renewal energy. Electricity is one of the major current energy forms boosting the economy of Ghana; it is mainly used in the industrial sector, followed by the residential and commercial (non-residential) sectors. In 2010, the industrial, residential and commercial sectors accounted for $46 \%, 40 \%$ and $14 \%$ respectively of the total electricity end-use in Ghana. The electricity distribution infrastructure is extensive and provides access to about $66 \%$ of Ghana's population (Ministry of Energy Ghana, 2010) [6] with a large proportion in urban areas. Despite the huge consumption of electricity by industries, residents and commercial sectors, it can be suggested that the large consumption of electricity by the various sectors can be a contributory factor to the power crisis that the country experienced between 2013 to 2015 which threatened Ghana's 
economy. Thus a load shedding management was implemented to rationalize electricity for consumers in the industry and residential users. The load schedule management by the electricity provider (Electricity Company of Ghana) has had serious effects on the country's GDP due to the energy crisis where demand outstrips supply. The need for energy conservation among Ghanaians, particularly in the wake of the worsening energy crises in 2015 cannot be over emphasized. The Energy Commission (E.C), the mandated body is to ensure energy efficiency in the country as well educate electricity consumers on energy conservation and the use of sustainable renewal energy. It has played some significant role in educating consumers on energy conservation tips. Some modern technology has been introduced to help create energy conservation habits among consumers. Smart Energy Monitors (SEM) is a technology that has been introduced in recent times as a way to help consumers conserve energy and to use electricity efficiently when needed. With the emergence of modern technology that is ubiquitous in our daily life activities, SEM is being proposed and adopted across several countries around the globe as a way to reduce electricity consumption and ensure energy efficiency for the future generation.

\section{Background}

Smart Energy Monitors (SEM) is a technology that has been introduced as a way to help consumers conserve energy and to use electricity efficiently when needed. Smart Energy Monitors (SEM) help individuals to identify their home's energy-hungry habits, where you can have an automated device that allows you to see how much energy you are consuming whenever appliances are switched on in real time. It gives the cost of the energy consumed by each electronic appliance in a household and as well also gives you some energy-saving tips. An example of SME is the Current Cost-Envi.

The Envi device is type of smart energy monitor that measures the electricity consumptions of electrical appliance connected to it. The device has a sensor coding recognition inbuilt in it that measures the electricity consumption and displays it on a bar graph on a viewable screen. It then calculates the cost of consumption for the electric appliance connected to it. The Envi device is manufactured by Current Cost (HK) Ltd.

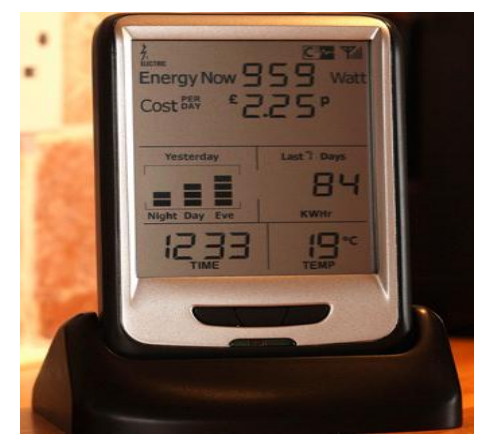

Current cost-Envi [7] 
This study investigates how the use of smart energy monitors can help conserve energy electricity in our homes. In line with this the study goes further to examine conservation among Ghanaian residents, challenges of energy conservation among Ghanaians in the catchment area (Ashongman) and how policy makers in Ghana can encourage the use of SEM technology in our homes. Some publications have suggested that, lack of policy frameworks by government on energy conservation methods and management has led to the power crisis which Ghana had experienced in 2015. This support the assertion made by (UNIDO, 2011) [8] that citizens and industries in Ghana are far behind in the adoption of energy efficiency and management measures and as such, missing the benefits of implementation in order to conserve energy. It can also be suggested that there is lack of a policy framework on energy conservation in the energy sector or no energy conservation habits by electricity consumers in Ashongman. This is one of the reasons the study seeks to find out. Another reason for conducting the study is to investigate electricity consumers' use of Smart Energy Monitors (SEM), its applications in homes, which can help shape up their energy conservation habits. One of the key objectives of this study is to investigate the use of SEM technology for energy conservation among people residing in Accra. This is because the city has a high population of electricity consumers on the national grid. We selected the Ashongman community in the Ga East municipality of Greater Accra. The main reason why Ashongma was selected purposely for the survey is that we wanted a cosmopolitan area in Accra that has middle-income, lower and elite people living in the same community. Another reason is that Ashongman is easily accessible within the heart of Accra with a growing population in the capital.

The significance of the study is that we seek to find out energy conservation among Ghanaian residents in Accra and also investigate how the use of SEM technology can help users conservation energy. This study is quite novel because not much research has been done in the area of using smart energy monitors technology for energy conserve in Ghana. There is also little literature on energy efficiency in Ghana whilst other studies done only examine energy production capacity in Ghana. The results from this study will be unique because it can lead to a policy formulation on the use of SEM technologies for energy conservation from the ECG and the Energy commission. This will be a key step in making the country energy efficient through the smart SEM technology.

\subsection{Problem Statement}

Ghana has experienced severe energy crisis in the past year of 2013 to 2015. The load schedule management by the Electricity Company of Ghana (ECG) has had serious effects on the economy due to electricity shortfall where demand exceeded supply. The issue of energy conservation among electricity consumers according to the ECG is a contributing factor to the problem where the electricity provider is not able to meet the demand of consumers. The problem state- 
ment of this study is to investigate energy conservation among residents of Ashongman in Accra and the use of Smart Energy Monitors technology to aid in electricity conservation.

\subsection{Objectives of the Study}

The motivation of this research study is to investigate the energy conservation and the use of Smart Energy Monitor Technology for energy conservation among residents in Ashongman in the Ga East Municipal Assembly in Greater Accra. The objectives have been designed as; to find out the energy saving habits among residence in Ashongman and to investigate the awareness and use of Smart Energy Monitor Technology among residence. We selected Ashongman community in the Ga East Municipality of Greater Accra. The main reason why Ashongman was selected purposely for the survey is that we wanted a cosmopolitan area within Accra that has different kinds of people from the middle-income, lower and elite living in the same community. Another reason why Ashongman was selected for the study is because it is located close to central Accra and easily accessible. The other objective of the study is to find out from the Energy Commission and the Electricity Company of Ghana on the effectiveness of using of SEMs for energy conservation for consumers.

\section{Related Works}

The use of electric power is a major prerequisite for the economic growth of a country. Economic systems operate based on the energy produced and the ability to get access to it that is determined by the level of energy production and the level of energy consumption for industries. [9] The need for electricity conservation is very essential in order to reduce the consumption of electric power and to ensure less energy used for services. Electricity conservation is very essential due to the increase cost of energy production. Electricity consumption in sub-Saharan countries is relatively low where in sub-Saharan Africa (that excludes South Africa) the average electricity consumption per capital in the year 2000 is $112.8 \mathrm{kwh}$. [10] Although electricity consumption is quite low where some countries in sub-Saharan Africa consume only a small fraction of electric power, the increase in urbanization will result in higher electricity consumption. Therefore electric power consumption is projected to go up increase as the urban dwellers increase and as many factories come on stream. The use of smart metering or energy monitors as a form of smart metering has been adopted by some governments in Europe, for instance the "The UK government has announced a national roll-out of smart meters in the coming decade and is, together with major energy supply companies, trialling various smart meter and display technologies via its Energy Demand Research Project (EDRP) which involves over 50,000 UK households (Ofgem, 2009)" [11] The goal of that project was to deploy smart metering among households in UK to help consumers become more energy efficient. A study was done in the Netherlands over a 15 -month period by indigenous energy monitors in that country. The study car- 
ried out by HEMS in the Netherlands examined the energy saving habits among consumers where there was a focus on energy saving habits which showed there was a $7.8 \%$ savings of electricity consumption among consumers after 4 months. [12] This study presented the enormous benefits of smart meters to assist electricity consumers to conserve energy and save the cost. Countries across the globe continue to outline policies and programme to help their citizens conserve and use energy more efficiently.

\section{Energy Conservation in Ghana}

The Energy Commission of Ghana through partnership with the UNDP has started a programme to campaign among consumers on the need to use energy efficient electrical appliances. One of the core aims of the programme is to create the awareness among Ghanaians about the high consumption of old appliances such as refrigerators. The campaign, therefore encourage electricity consumers to exchange their old electric appliance (refrigerators) in exchange for new refrigerators which are more energy efficient. [13] The program has achieved significant success with some citizens replacing their high-energy demand appliances. The UNDP programme continues to collaborate with the Government of Ghana so as to promote Ghana's journey towards achieving a green economy with low-carbon. "As part of the UN's Sustainable Energy for All (SE4All) initiative, Ghana has embarked on a UNDP-supported action plan to provide universal energy access, improve energy efficiency and increase renewable energy for all Ghanaians by 2030.” [14] The government of Ghana still works with other state agencies to encourage its citizens on the need for energy conservation. It is therefore significant that this study looks at energy conservation among Ghanaian citizens living Ashongman and how the use of SEM technology will play a significant role in Ghana's desire to achieve energy efficiency among its citizens.

\section{Methodology}

The main instrument used to collect the needed data was postal questionnaire. Questionnaires were used in this study because it is the most appropriate technique to achieve the objectives of the study, in the sample area at Ashongman in the Ga East Municipal Assembly. In gathering our data for the study we adopted a purpose survey to address the key research questions of the paper. The main research question for this study is how the SEM technology can be used to conserve energy among the residents of Ashongman. By using postal questionnaire, the research questions were administered among residents of Ashongman and some technical staff of both the ECG and the Energy Commission. The data analysis from the response of the survey was done using SPSS software package to analyze the responses. The sample size for the study was 69, comprising 50 residents of Ashongman and 19 technical staff from both the E.C.G and the Energy Commission. The sample size was estimated based on the formula $n=\frac{\delta^{2} \times \sigma^{2}}{E^{2}}$ where $\delta$ =confidence interval confidence 
interval $95 \%$ and $\sigma=$ approximated standard deviation(21) and

$E=$ error $\operatorname{rate}(5 \%) n=$ sample size.

$$
n=\frac{1.96^{2} \times 21^{2}}{5^{2}} \geq \frac{3.9 \times 441}{25}=68.7 \sim 69 \text { participants with a } 5 \% \text { margin of error. }
$$

Thus, the total sample size of the study was 69 participants. The study considered a total of 50 residents in Ashongman estates and 19 technicians (staff) of both the Electricity Company of Ghana (E.C.G) and the Energy Commission (E.C). This was to ensure good sample views of residents on the smart energy monitors with emphasis on energy conservation.

\section{Empirical Findings and Analysis}

The data presentation, analysis and discussion of results of the fieldwork carried out in the research study. The data collected is analysed and the results are presented in tables, pie charts and graphs supported with description and explanations. The analysis and description of the results for the study is illustrated below;

Does your utility provider give you any tips on energy conservation?

Figure 1 illustrates whether the electricity provider (E.C.G) gives any energy conservation tips to electricity consumers in Ashongma. The pie chart shows that $11(16 \%)$ answered Yes, the utility provider gives them energy conservation tips whilst 39 (84\%) said No, E.C.G does not give them energy saving tips.

Table 1 illustrates the respondents on their knowledge or awareness of smart energy monitor technology for energy conservation.

Figure 2 and Table 2 indicates that 8 of the respondents that have used smart energy have attested to the fact that it has helped them conserve energy in their homes.

\section{Factors that makes it challenging in conserving energy at home}

Figure 3, The respondents indicate the factors that make it difficult to conserve energy at home were, using gadgets whose voltage are high is $9(18 \%)$ respondents; using too many electric gadgets is 7 (14\%); lack of education on energy conservation $24(48 \%)$. The respondents are of the view that lack of public education on energy conservation is a major challenge in conserving energy at homes whilst $4(8 \%)$ of respondents said electricity bills still remain high irrespective of conserving energy. Finally, 6 (12\%) of respondents said inexperience in energy conservation is a contributing factor.

\section{Ways to conserve energy among electricity consumers}

The figure below describes the ways by which consumers can conserve energy.

Figure 4, the respondents indicate the ways in conserving energy is by putting gadgets off when leaving the house. This is suggested by 23 (46\%) respondents. 7 (14\%) respondents suggested that electricity consumers should avoid using gadgets with high voltage consumption. $12(24 \%)$ of respondents said educating people on energy conservation will help conserve energy. 5 (10\%) of respondents suggested that electricity consumers should avoid using old gadgets that con- 
sume a lot electricity, while a little as $3(6 \%)$ of respondents said electricity can be conserve if technologies that will put gadgets off automatically if not in use are introduced in homes.

Table 1. Awareness of electricity consumers (respondents) on Smart Energy Monitors.

\begin{tabular}{ccc}
\hline Responses & Frequency & Percentage (\%) \\
\hline Yes & 11 & 16.0 \\
No & 39 & 84.0 \\
Total & $\mathbf{5 0}$ & $\mathbf{1 0 0 . 0}$ \\
\hline
\end{tabular}

Source: Field Survey, 2016.

Table 2. Have respondents used SEM?

\begin{tabular}{ccc}
\hline Responses & Frequency & Percentage (\%) \\
\hline Yes & 8 & 72.7 \\
No & 3 & 27.3 \\
Total & 11 & 100.0 \\
\hline
\end{tabular}

Source: Field Survey, 2016.

Does your utility providers (E.C.G) gives you any tips on energy conservation

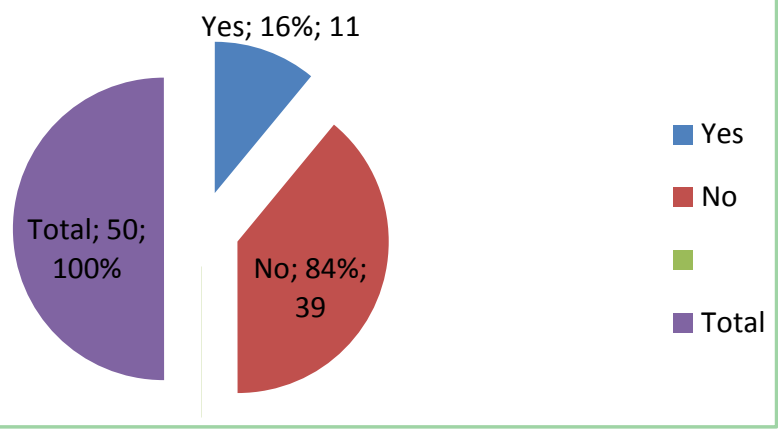

Figure 1. Source; field work (2016).

Has the use of SEM aided in conserving energy

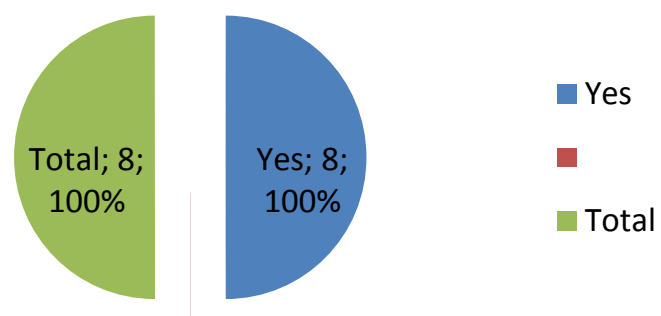

Figure 2. Source: Field Survey (2016). 


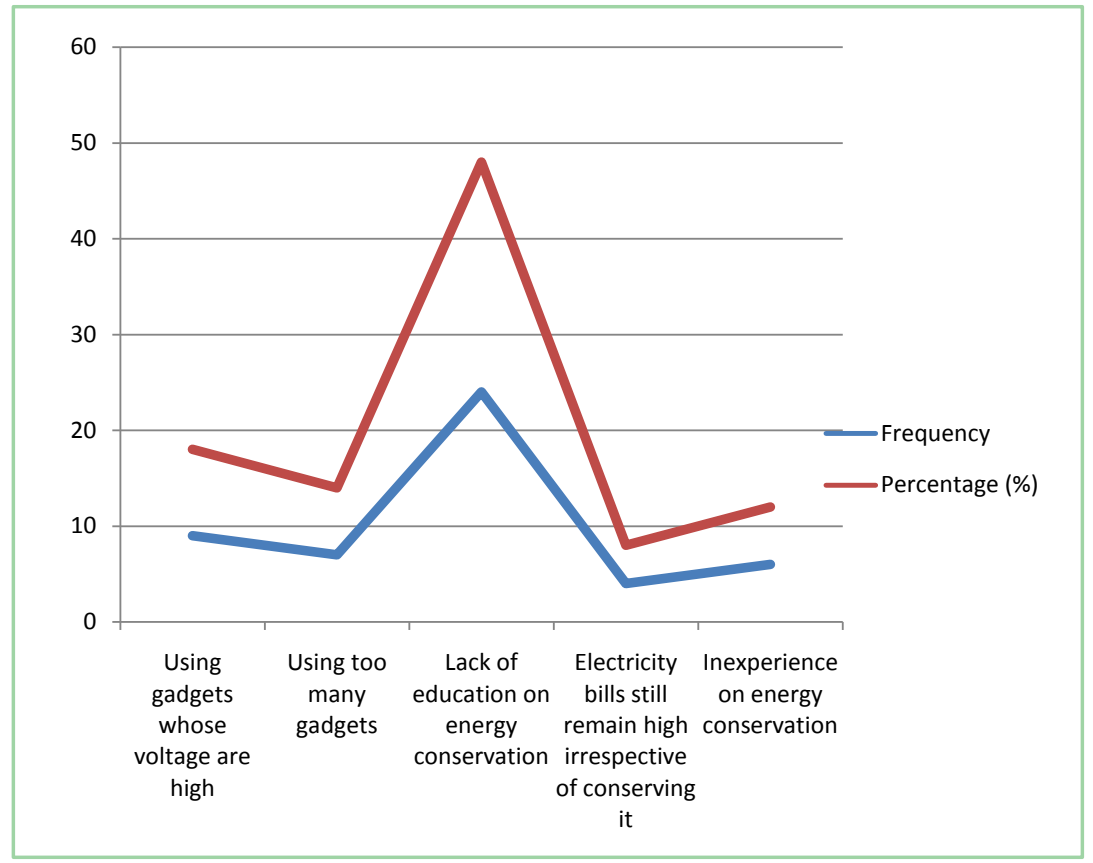

Figure 3. Factors that makes it challenging in conserving energy at home.

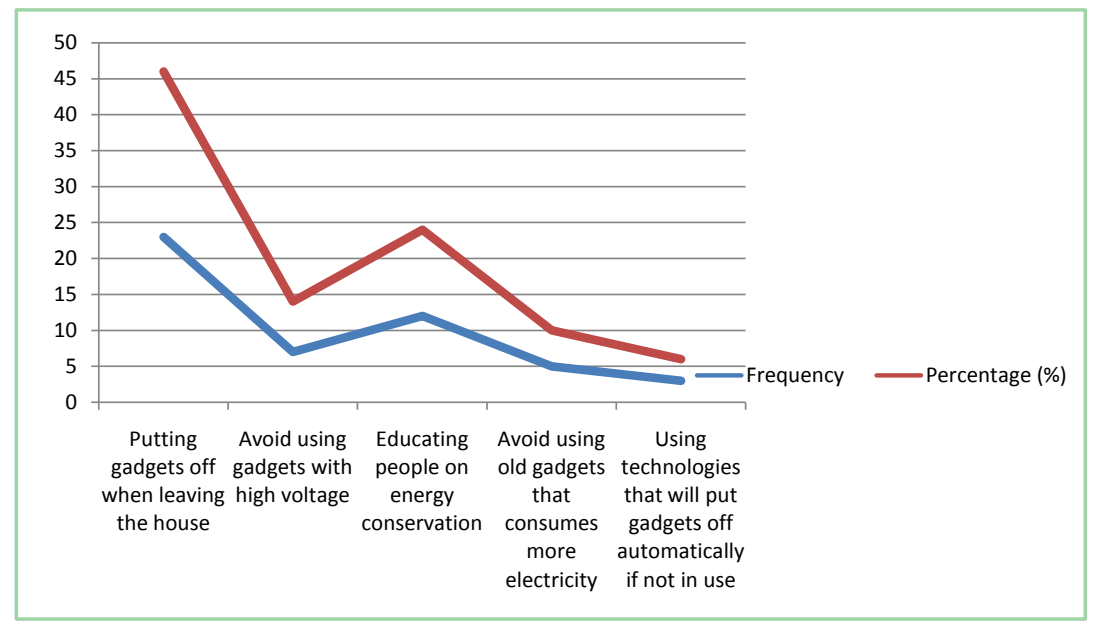

Figure 4. Ways to conserve energy among electricity consumers.

\section{Results obtained from E.C.G and the Energy Commission}

The second part of the analysis is from the Electricity Company of Ghana and the Energy Commission of Ghana. Below is an analysis of the responses from technicians (staff) of ECG and Energy Commission.

\section{Behavioral issues with electricity conservation among Ghanaians}

Figure 5, illustrates the behavior issues of electricity consumers on energy conservation form the perspective of the technical staff of E.C.G and the Energy Commission.

Table 3 indicates responses from both the ECG and Energy Commission if they have Smart Energy Monitors to monitor the use of electricity. As little as 5 (26.3\%) of respondents said No, they do not know about SEMs to monitor their 
electricity consumption. As many as $14(73.7 \%)$ of respondents answered in the affirmative and are aware of SEM for energy conservation. It can be concluded that majority of technical staff at both ECG and Energy Commission are aware of the SEM technology and its benefits for electricity consumers to conserve energy.

\section{Can the use of SEMs help Ghana manage it energy demands}

The graph below describes how the use of smart energy monitors can help electricity consumers in Ghana to conserve energy.

Figure 6 The response reveals that 10 (52.6\%) of respondents said the use of SEM can help Ghana manage it electricity demands, 3 (15.8\%) of respondents said may be, installing SEMs can help, 5 (26.3\%) of respondents said yes, installing SEM can help but it will come with a huge cost which may not be cost effective for both the electricity provider and the consumer. The remaining 1 (5.3\%) did not provide an answer. It can be deduced that majority of respondents said that the use of SEM can help manage Ghana's electricity demands and in the long term help electricity consumers to conserve energy. It also indicates that even though some of the technical staff agree on the benefits of SEM for energy conservation, the cost associated with it may not make worth considering.

Table 4 the respondents reveal some challenges electricity consumers face in conserving energy. 4 (21.0\%) of respondents said lack of advertisement makes it difficult for consumers to be educated on the need of conserving energy among consumers. 5 (31.6\%) of respondents said the lack of using SEMs, is also a challenge electricity consumers face in conserving energy. 9 (47.4\%) of respondents said the lack of an energy conservation policy makes it difficult for consumers to conserve energy. There is therefore the need for a comprehensive policy framework to allow both ECG and the Energy Commission to ensure energy conservation for electricity consumers to energy efficient.

Table 3. Does the E.C.G or Energy Commission (E.C) have SEM to monitor the use of energy.

\begin{tabular}{ccc}
\hline Responses & Frequency & Percentage (\%) \\
\hline No & 5 & 26.3 \\
Yes & 14 & 73.7 \\
Total & 19 & 100.0 \\
\hline
\end{tabular}

Source; field work (2016)

Table 4. Challenges of electricity consumers face in conserving energy.

\begin{tabular}{ccc}
\hline & Frequency & Percentage (\%) \\
\hline Lack of advertisement in conserving energy & 4 & 21.0 \\
Lack of using SEM in conserving energy & 6 & 31.6 \\
Lack of energy conservation policy & 9 & 47.4 \\
Total & 19 & 100 \\
\hline
\end{tabular}

Source; field work (2016). 


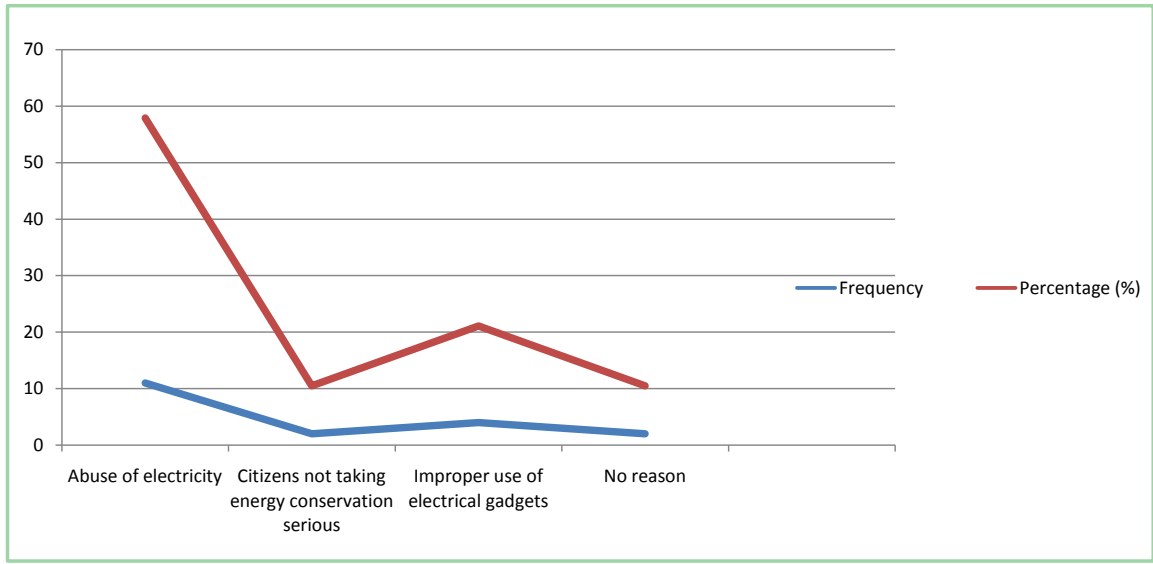

Figure 5. Behavioral issues with electricity conservation among Ghanaians.

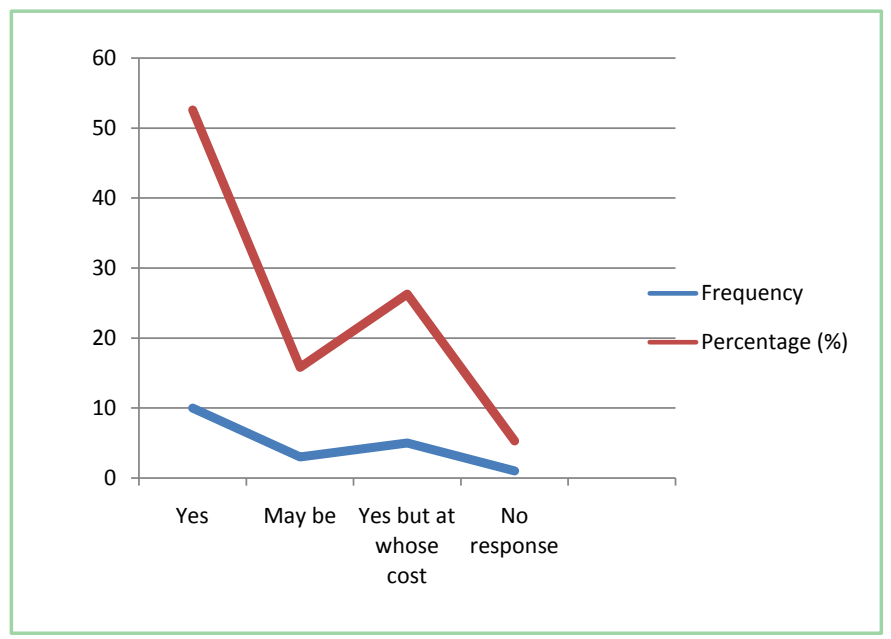

Figure 6. Can the use of SEMs help Ghana manage it energy demands.

\section{Conclusion}

A detailed analysis of the study findings indicates there is the need for a policy framework on energy conservation among electricity consumers. Some of the respondents in the study are of the view that putting lights outs and turning off electrical gadgets can help conserve electricity. A few respondents have used SEM and it has helped them conserver energy. It is clear the majority of respondents are not aware of SEMs and have not used it before. Respondents admit that they have not used the SEMs before because, they have not heard about it and thus do not know the benefits of using SEMs. The response from the study also indicates that some factors that make it difficult in conserving energy at home are, using gadgets whose voltage is high, using too many gadgets, lack of education on energy conservation. Energy conservation is vital for the development of every nation. In order to help conserve energy, the Electricity providers (E.C.G) and the Energy Commission should educate energy consumers on energy conservation tips. In the final analysis, it is estimated that Ghana will be able to save approximately $3 \%$ to $5 \%$ of power per annum if the use of the SEMs 
technology is adopted with the combination of other energy saving habits being adopted by consumers. Policy makers need to consider deploying the SEMs technology to individual households and educating consumers on the benefits of using it. Finally, Ghana, a lower-middle income country needs to be more energy efficient if it is to boost its economic growth and become the hub of energy export in the sub-region. There should be an effective campaign to educate electricity consumers to use SEMs as a technology for energy conservation and an effective policy to support it.

\section{Acknowledgements}

We like to acknowledge Mr. William Boateng, a senior researcher and PRO of the Electricity Company of Ghana (E.C.G) for his contribution in conducting this study. We are also grateful to Mr. Amoah of the Energy Commission of Ghana for his insightful input in the work.

\section{Conflicts of Interest}

The authors declare no conflicts of interest regarding the publication of this paper.

\section{References}

[1] Chakarvarti, K.K. (2011) ISO 50001: Energy Management Systems Standards. Bureau of Energy Efficiency, New Delhi. http://knowledgeplatform.in/wp-content/

[2] Dai, X., Wu, Y., Di, Y. and Li, Q. (2009) Government Regulation and Associated Innovations in Building Energy Efficiency Supervisory Systems for a Large-Scale Buildings in a Market Economy. Energy Policy, 37, 2073-2078. https://doi.org/10.1016/j.enpol.2009.02.008

[3] (2015) How Smart Energy Monitors Work: Electrical Energy Monitors by Chris Woodford.

[4] Energy Commission (Ghana) (2015) 2015 Energy (Supply and Demand) Outlook for Ghana.

[5] GRIDCO Ghana, Ghana Peak Load + Exports (2014)

[6] Ministry of Energy, Ghana. http://www.energymin.gov.gh

[7] Current Cost-Envi: (2015) http://www.currentcost.com/

[8] (2015) UNDP Supports National Efforts to Conserve Energy in Ghana|UNDP in Ghana. http://www.gh.undp.org

[9] Sklyarov, D.E., Kustov, E.F. and Lozenko, V.K. (2015) Energy Efficiency and Conservation Economies. iBusiness, 7, 98-109. https://doi.org/10.4236/ib.2015.72012

[10] Wolde-Rufael, Y. (2006) Electricity Consumption and Economic Growth: A Time Series Experience for 17 African Countries. Energy Policy, 34, 1106-1114. https://doi.org/10.1016/j.enpol.2004.10.008

[11] Martiskainen, M. and Ellis, J. (2007) The Role of Smart Meters in Encouraging Behavioural Change. Sussex Energy Group, SPRU (Science and Technology Policy Research), University of Sussex. http://sro.sussex.ac.uk/59518/

[12] van Dam, S.S., et al. (2010) Home Energy Monitors: Impact over the Medium-Term. 
https://www.tandfonline.com/doi/abs/10.1080

[13] UNDP Supports National Efforts to Conserve Energy in Ghana|UNDP in Ghana. http://www.gh.undp.org

[14] Savoring the Gains from the Refrigerator Rebate Scheme in Ghana|UNDP in Ghana. http://www.gh.undp.org 